\title{
Genome-wide association study for claw disorders and trimming status in dairy cattle
}

\author{
D. van der Spek, ${ }^{1}$ J. A. M. van Arendonk, and H. Bovenhuis \\ Animal Breeding and Genomics Centre, Wageningen University, PO 338, $6700 \mathrm{AH}$, Wageningen, the Netherlands
}

\begin{abstract}
Performing a genome-wide association study (GWAS) might add to a better understanding of the development of claw disorders and the need for trimming. Therefore, the aim of the current study was to perform a GWAS on claw disorders and trimming status and to validate the results for claw disorders based on an independent data set. Data consisted of 20,474 cows with phenotypes for claw disorders and 50,238 cows with phenotypes for trimming status. Recorded claw disorders used in the current study were double sole (DS), interdigital hyperplasia (IH), sole hemorrhage ( $\mathrm{SH}$ ), sole ulcer (SU), white line separation (WLS), a combination of infectious claw disorders consisting of (inter-) digital dermatitis and heel erosion, and a combination of laminitis-related claw disorders (DS, SH, SU, and WLS). Of the cows with phenotypes for claw disorders, 1,771 cows were genotyped and these cow data were used for the GWAS on claw disorders. A SNP was considered significant when the false discovery rate $\leq 0.05$ and suggestive when the false discovery rate $\leq 0.20$. An independent data set of 185 genotyped bulls having at least 5 daughters with phenotypes $(6,824$ daughters in total) for claw disorders was used to validate significant and suggestive SNP detected based on the cow data. To analyze the trait "trimming status" (i.e., the need for claw trimming), a data set with 327 genotyped bulls having at least 5 daughters with phenotypes $(18,525$ daughters in total) was used. Based on the cow data, in total 10 significant and 45 suggestive SNP were detected for claw disorders. The 10 significant SNP were associated with SU, and mainly located on BTA8. The suggestive SNP were associated with DS, IH, SU, and laminitis-related claw disorders. Three of the suggestive SNP were validated in the data set of 185 bulls, and were located on BTA13, BTA14, and BTA17. For infectious claw disorders, SH, and WLS, no significant
\end{abstract}

Received April 29, 2014.

Accepted October 28, 2014.

${ }^{1}$ Corresponding author: dianne.vanderspek@wur.nl or suggestive SNP associations were detected. For trimming status, 1 significant and 1 suggestive SNP were detected, both located close to each other on BTA15. Some significant and suggestive SNP were located close to SNP detected in studies on feet and leg conformation traits. Genes with major effects could not be detected and SNP associations were spread across the genome, indicating that many SNP, each explaining a small proportion of the genetic variance, influence claw disorders. Therefore, to reduce the incidence of claw disorders by breeding, genomic selection is a promising approach.

Key words: association study, hoof lesion, HolsteinFriesian

\section{INTRODUCTION}

Breeding goals in dairy cattle focus not only on production traits, but increasing emphasis is also on health and durability traits (Miglior et al., 2005). Claw disorders are common in dairy cattle with a prevalence of more than 70\% (e.g., Manske et al., 2002; van der Waaij et al., 2005). Claw disorders are important because of welfare issues (Enting et al., 1997) and economic impact (Bruijnis et al., 2012a,b). A trait currently not considered but of interest is the need for claw trimming. Some cows need more claw trimming than others and van der Spek et al. (2013) showed that the need for trimming, or "trimming status," is a heritable trait. High scores for trimming status reflect that daughters of a bull need more trimming, which is unfavorable and which is positively correlated with increased occurrence of claw disorders (van der Spek et al., 2013).

Genetic selection for reduced claw disorders is difficult because the disorders are not routinely recorded. Indicator traits for claw disorders, which may be more accurate and easier to obtain, are lameness (Laursen et al., 2009; Weber et al., 2013) and feet and leg conformation traits (van der Waaij et al., 2005; van der Linde et al., 2010). Scores for feet and leg conformation are routinely collected in most breeding schemes. Previous studies have detected QTL for lameness and feet and leg conformation (Ashwell et al., 1998a,b; Schrooten et al., 2000; Boichard et al., 2003; Buitenhuis et al., 2007). However, to the best of our knowledge, no link- 
age or GWAS have been reported on claw disorders. The bovine genome sequencing and the emergence of high-throughput genotyping technologies have made it possible to perform genome-wide association studies (GWAS, e.g., Tellam et al., 2009). Genome-wide association studies enable the detection of genetic variants associated with a particular trait or disease, using dense genome-wide markers, also known as SNP (Hirschhorn and Daly, 2005; Matukumalli et al., 2009). Performing a GWAS might add to a better understanding of the development of claw disorders and the need for trimming, when the underlying genetic background can be identified. A GWAS is a good method to detect SNP associations, but some of the results can be false positives. False-positive associations occur especially due to population structure (Goddard and Hayes, 2009). Even if population structure is accounted for in the analysis and stringent significance thresholds are used, false-positive results might occur due to the high chance of some unaccounted for data structure in livestock populations given the large number of tested SNP (Hayes, 2013). To eliminate false positives, associations detected in a GWAS study should therefore be validated in an independent population (Chanock et al., 2007; Hayes, 2013). Therefore, the aim of the current study was to perform a GWAS on several claw disorders in dairy cows and to validate the results for claw disorders based on an independent data set. In addition, a GWAS will be performed on the trait trimming status using daughter yield deviations (DYD) of bulls.

\section{MATERIALS AND METHODS}

Analyses were performed based on 2 data sets: one with genotyped cows and one with genotyped bulls. The data set with cows was based on genotyped cows, which also have phenotypes for claw disorders. These data will be referred to as the cow data. The data set with bulls was based on genotyped bulls that have daughters with phenotypes for claw disorders. Phenotypes of cows adjusted for systematic environmental effects were used to calculate the DYD for bulls. Phenotypes from genotyped cows used in the cow data were dropped from calculating DYD for bulls. In this case, no overlap exists in phenotypes between the 2 data sets. The DYD data of bulls were used to validate significant or suggestive SNP detected for claw disorders using the cow data and will be referred to as the bull validation data. The trait trimming status was analyzed with the bull data without removing phenotypes of genotyped daughters. The DYD were calculated and used as a phenotype for bulls. These data will be referred to as the trimming status data.

\section{Phenotypic Data on Claw Disorders}

After removing records of cows with both parents unknown or with 2 different trimming records on the same date ( $\mathrm{n}=6,374$ records), the data set contained 50,238 cows. The cows descended from 3,603 sires with an average of 14 daughters per sire. Phenotypes on claw disorders were collected by 6 professional claw trimmers, from January 2007 through February 2012, during routine visits on 574 dairy farms in France. The farmer decided which cows were to be trimmed, and as a result, not all cows present in a herd were trimmed. Information on parity, stage of lactation, and pedigree was available on all cows present in a herd at the moment of trimming (including the nontrimmed cows). Of the 50,238 cows, 20,474 had one or more claw trimming records and in total 29,994 claw trimming records were available. Trimming records were repeated within and across lactations; $69 \%$ of the cows had 1 trimming record, $20 \%$ had 2 trimming records, and $11 \%$ had 3 or more trimming records. Claw disorders were recorded for the hind legs and scored as a binary trait: $0=$ no claw disorder, $1=$ claw disorder in at least one hind leg. Recorded claw disorders used in the current study were double sole (DS), interdigital hyperplasia (IH), sole hemorrhage (SH), sole ulcer (SU), white line separation (WLS), and a combination of infectious lesions (DER) consisting of (inter-)digital dermatitis and heel erosion. The trimming status trait indicates whether a cow was trimmed (score 1) or not trimmed (score 0) during a visit by the claw trimmer on a specific date. The claw disorders and the trait trimming status are explained in more detail by van der Spek et al. (2013). van der Spek et al. (2013) showed moderate to high genetic correlations between laminitis-related claw disorders (DS, $\mathrm{SH}, \mathrm{SU}$, and WLS). Therefore, 4 laminitis-related claw disorders were combined by adding up the scores for the individual traits, resulting in a trait LAMIN, with scores ranging from 0 (no claw disorder) to 4 (all 4 claw disorders present). For trimming status, 50,238 cows with phenotypes were available, and for claw disorders 20,474 cows with phenotypes were available.

\section{Genotypic Data}

The DNA was extracted from blood or semen samples. Herds with at least $10 \%$ of the cows having claw disorders in previous years were identified and all cows on these herds trimmed in the second half of 2012 or first half of 2013 were sampled. Subsequently, all cows with trimming records available were genotyped. Genotypes of bulls were already available and were included when the bull had daughters with trimming records. In total, 1,771 Holstein-Friesian cows and 506 Holstein-Friesian 
bulls were genotyped with the Illumina BovineSNP50 BeadChip (Illumina Inc., San Diego, CA) for 54,609 SNP. All genotyped cows have phenotypic data available as well, and all genotyped bulls have daughters with phenotypic data. The genotyped cows were kept in 87 herds and descended from 434 sires of which 214 had genotypic data available. One bull had a call rate $<95 \%$ and was eliminated. Genotypes were analyzed using the Illumina GenomeStudio software. Quality control was performed on the genotypic data and a SNP was only included when the following criteria were met: (1) the minor allele frequency (MAF) $>2 \%$; (2) the percentage of missing genotypes across all samples $<5 \%$; (3) no strong deviation from Hardy-Weinberg equilibrium $\left(\chi^{2}\right.$ values $<600)$. The last criterion was included as a way to filter out poor-quality SNP. Extreme deviations from Hardy-Weinberg equilibrium are expected to be due to poorly called genotypes. Genotypes of bulls with fewer than 5 daughters with records on claw disorders were eliminated; the number of daughters per bull ranged from 5 to 905 . A total of 41,761 SNP for 1,771 cows, 327 bulls with phenotypes for trimming status of 6,824 daughters, and 185 bulls with phenotypes for claw disorders of 18,525 daughters were retained and available for analyses.

\section{Association Study for Claw Disorders-Cow Data}

The association of an individual SNP with a claw disorder was estimated using the following linear animal model:

$$
\mathbf{y}=\mathbf{X b}+\mathbf{Z}_{1} \mathbf{a}+\mathbf{Z}_{2} \mathbf{p e}+\mathbf{e}
$$

where $\mathbf{y}$ is a vector of observations of the trait; $\mathbf{b}$ is a vector of fixed effects, including herd, year-season of trimming (season is defined as spring = March to May; summer $=$ June to August; autumn $=$ September to November; winter $=$ December to February), parity at trimming (consisting of 4 classes; $1,2,3$, and $\geq 4$ ), lactation stage at trimming (consisting of 10 classes; class 1 to 9 are $50 \mathrm{~d}$ each, with the first class from 1 to $50 \mathrm{~d}$, the second class from 50 to $100 \mathrm{~d}$, and so on, and cows with lactation stage $\geq 450 \mathrm{~d}$ were assigned to class 10 ), and SNP (SNP is treated as a class variable with 2 or 3 classes, depending on the number of genotypes); $\mathbf{X}$ is the incidence matrix for the fixed effects; $\mathbf{a}$ is a vector of animal additive genetic effects and is assumed to follow a multivariate normal distribution $\sim \mathrm{N}\left(0, \mathbf{A} \sigma_{a}^{2}\right)$, where $\mathbf{A}$ is the additive genetic relationships matrix which consisted of 56,867 animals and $\sigma_{a}^{2}$ is the additive genetic variance; pe is a vector of permanent environ- mental effects $\sim \mathrm{N}\left(0, \mathbf{I} \sigma_{p e}^{2}\right)$, and $\mathbf{e}$ is a vector of residual effects $\sim \mathrm{N}\left(0, \mathbf{I} \sigma_{e}^{2}\right)$, where $\mathbf{I}$ is the identity matrix, $\sigma_{p e}^{2}$ is the permanent environmental variance and $\sigma_{e}^{2}$ is the residual variance; $\mathbf{Z}_{1}$ is the incidence matrix relating observations to animal effects, and $\mathbf{Z}_{2}$ is the incidence matrix relating observations to permanent environmental effects.

A linear model was used for the binary traits as it is computationally more feasible as compared with a threshold model. Also, Pirinen et al. (2013) showed that for a GWAS, the logistic regression model can be accurately approximated by the linear model. The heritabilities for claw disorders were fixed at the estimates obtained from the variance component analysis as given by van der Spek et al. (2013). Variance components for LAMIN, combining the 4 laminitis-related claw disorders, were estimated using the model described by van der Spek et al. (2013) and resulted in a heritability of $0.07( \pm 0.01)$ and a phenotypic variance of 0.34 . Analyses were performed using ASReml v3.0 (Gilmour et al., 2009).

The significance threshold for the GWAS was adjusted for multiple testing using the false discovery rate (FDR). The qvalue package in $\mathrm{R}$ statistical software (Storey and Tibshirani, 2003) was used to obtain the FDR. A FDR $\leq 0.20$ will be referred to as suggestive and a FDR $\leq 0.05$ as significant in our study.

When a SNP genotype contained less than 5 cows, the records for this genotype were omitted and the association for this SNP was reevaluated. When the $P$-value is $\geq 0.05$, the SNP will be omitted from further analysis.

\section{Association Study-Bull Data}

The association of an individual SNP with a claw disorder or trimming status was estimated using the following linear animal model:

$$
\mathbf{y}=\mathbf{X b}+\mathbf{Z}_{1} \mathbf{a}+\mathbf{e}
$$

where $\mathbf{y}$ is a vector of observations of the trait; $\mathbf{b}$ is a vector of the fixed effect SNP (SNP is treated as a class variable with 2 or 3 classes, depending on the number of genotypes); $\mathbf{X}$ is the incidence matrix for the fixed effect; $\mathbf{a}$ is a vector of animal additive genetic effects and is assumed to follow a multivariate normal distribution $\sim \mathrm{N}\left(0, \mathbf{A} \sigma_{a}^{2}\right)$, where $\mathbf{A}$ is the additive genetic relationships matrix, which consisted of 2,172 animals, and $\sigma_{a}^{2}$ is the additive genetic variance; $\mathbf{e}$ is a vector of residual effects $\sim \mathrm{N}\left(0, \mathbf{R} \sigma_{e}^{2}\right)$, where $\mathbf{R}$ is a diagonal matrix 
with the reciprocal of the reliabilities as diagonal elements and $\sigma_{e}^{2}$ is the residual variance; $\mathbf{Z}_{1}$ is the incidence matrix relating observations to animal effects.

Variance components for trimming status and claw disorders were fixed at the estimates obtained from analyses with a weighted univariate linear animal model, with DYD as the dependent variable and animal as a random additive genetic effect, using reliabilities as weights.

Validation of Suggestive SNP for Claw Disorders. In the bull validation set for claw disorders, the effect of a suggestive or significant SNP detected in the cow data was considered validated if it showed a significant effect $(P \leq 0.05)$ and if the allele with the favorable effect was identical in both analyses.

Trimming Status. Based on the trimming status data a SNP association was significant if FDR $\leq 0.05$ and suggestive if FDR $\leq 0.20$. When a SNP genotype contained fewer than 5 bulls, the records for this genotype were omitted and the association for this SNP was reevaluated. When the $P$-value is $\geq 0.05$, the SNP will be omitted from further analysis.

\section{RESULTS}

\section{SNP Analysis on Claw Disorders with the Cow Data}

The results of the genome-wide association studies for the different claw disorders are shown in Figure 1. In total, 17 significant and 77 suggestive SNP were detected. When a genotype contained less than 5 cows, the SNP was reevaluated by omitting the records for this genotype and reevaluating the association for this SNP. Of the 94 significant and suggestive associations, 39 were reevaluated. None of the reevaluated associations had a $P$-value $\leq 0.05$ and were consequently omitted from further analysis; they are also not shown in Figure 1. In total, 10 significant and 45 suggestive SNP remained and will be discussed in more detail. Ten significant and 20 suggestive SNP associations were detected for SU. One suggestive association was detected for DS, 17 for IH, and 7 for LAMIN, whereas DER, WLS and SH did not show any suggestive SNP association (Figure 1). For 1 significant and 1 suggestive SNP, no records were present for 1 of the 3 genotypes due to low MAF. The chromosome number, position, SNP name, and the number of cows per genotype for the 10 significant SNP with associated claw disorder are shown in Table 1 and for the 45 suggestive SNP in Appendix Table A1. The total number of cows per SNP differs slightly due to missing SNP genotypes. The $-\log _{10} P$-values for the significant SNP associations range from 4.67 to 6.79 (Table 1). The most significant SNP $\left(-\log _{10} P\right.$-value of 6.79) was associated with an increase in incidence of SU. The AA genotype had an effect size of 0.28 and the BB had an effect size of 0.01 , corresponding to an increase in incidence of SU with $27 \%$ when a cow has genotype AA as compared with genotype BB. For other significant SNP, the difference between both homozygote genotypes corresponded to an increase in incidence of SU ranging from 10 to $38 \%$.

The 10 significant SNP were located on BTA8, BTA10, BTA11, BTA18, and BTA22. Most significant SNP $(n=5)$ were located on BTA8. The 45 suggestive SNP were located on 20 different chromosomes: BTA1, BTA5 to BTA15, BTA17, BTA18, BTA20 to BTA24, and BTA26. Most suggestive SNP were detected on BTA8 $(\mathrm{n}=10)$, BTA9 $(\mathrm{n}=5)$, and BTA20 $(\mathrm{n}=5)$. Estimated SNP effects of the 10 significant SNP are presented in Table 1, and estimated SNP effects of the 45 suggestive SNP are presented in Appendix Table A1.

\section{SNP Analyses on DYD of Bulls}

Validation of Suggestive SNP for Claw Disorders. Three of the suggestive SNP detected in the GWAS based on cow data were confirmed based on the bull validation data. These SNP were ARS-BFGLNGS-113540 on BTA13 $(P=0.02)$, ARS-BFGLNGS-4929 on BTA14 $(P=0.02)$, and BTB-00678060 on BTA17 $(P=0.02)$. The favorable allele was identical in the cow data as in the bull validation data.

SNP Associations with Trimming Status. The GWAS results for trimming status are shown in Figure 2. Four significant and 6 suggestive SNP associations were detected for the trait trimming status. Eight SNP had one genotype containing 5 or less bulls and therefore these associations were reevaluated by omitting the smallest genotype. None of the reevaluated associations had a $P$-value $\leq 0.05$ and were consequently omitted from further analysis. Two suggestive SNP associations, both located on BTA15, remained. Figure 2 shows the results for trimming status after the reevaluation. The $-\log _{10} P$-values were 5.13 for SNP UA-IFASA-6898 (32713410 bp) and 4.99 for SNP ARSBFGL-NGS-57210 (32637662 bp).

\section{DISCUSSION}

\section{SNP Associations with Claw Disorders in Cows}

In the cow data set, 10 significant and 45 suggestive SNP were detected for DS, IH, SU, and LAMIN. The 55 significant and suggestive SNP were located on 20 different chromosomes. This suggests that claw disorders are influenced by many genes dispersed across the entire genome, each explaining a small part of the genetic variance. Caution must be taken because it might 

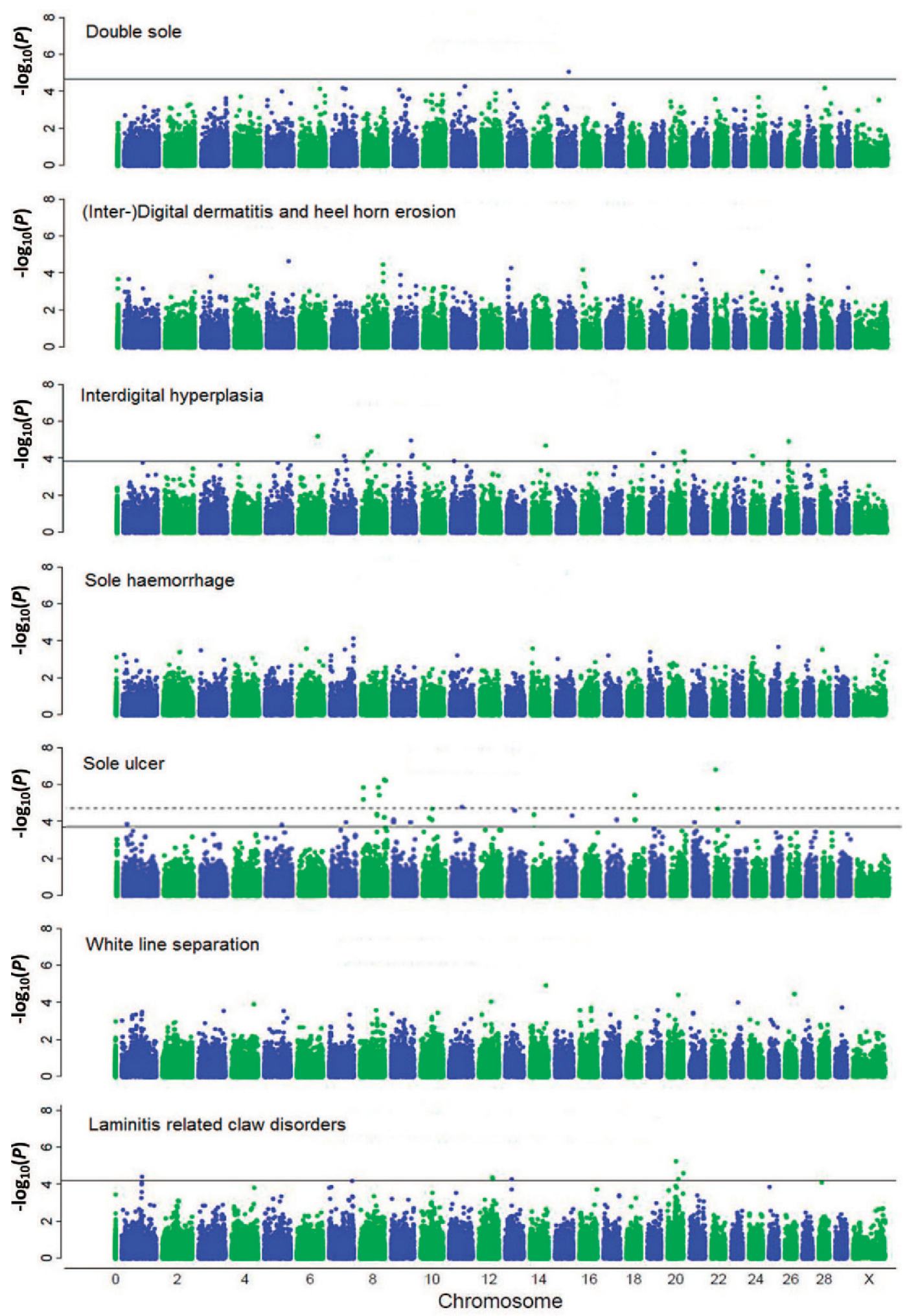

Figure 1. Genome-wide association study of claw disorders and the combination of laminitis-related claw disorders (double sole, sole hemorrhage, sole ulcer, and white line separation). The false discovery rate was set at 0.05 for significant SNP (dashed line) and 0.20 for suggestive SNP (solid line). Color version available online. 


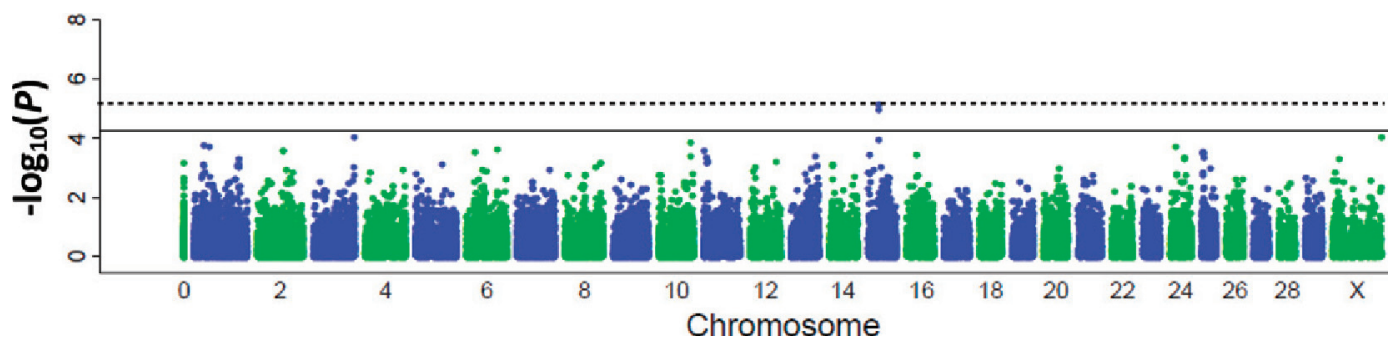

Figure 2. Genome-wide association study for trimming status using daughter-yield deviations of bulls. The false discovery rate was set at a threshold of 0.05 for significant SNP (dashed line) and 0.20 for suggestive SNP (solid line). Color version available online.

be that not all relevant SNP were detected and some SNP might be false positives due to the low number of animals and many SNP suffering from low MAF, as will be discussed later. No suggestive or significant SNP were detected for claw disorders DER, SH, and WLS. Associations with these claw disorders were apparently too small to be detected in the present data set. A larger number of animals will increase the power to detect associations, especially for SNP explaining a small proportion of the genetic variance of the trait (e.g., Visscher, 2008; Goddard and Hayes, 2009).

We chose to calculate a trait-based FDR instead of an experiment-based FDR. Adjusting the significance threshold to account for testing multiple traits has some disadvantages because it would penalize studies that report on multiple traits and it would encourage authors to write papers for each trait separately.

Claw disorders have a low heritability (ranging from 0.02 to 0.14, van der Spek et al., 2013). With 1,771 genotyped cows and assuming a squared correlation $\left(\mathrm{r}^{2}\right)$ between marker and QTL of 0.2, allele frequencies of both marker and QTL of 0.5, and a type I error equal to 0.001 , the power to detect a QTL can be calculated [using the function luo.ld.power (Luo, 1998) from the package ldDesign for the statistical software $\mathrm{R}$ (Ball, 2010)]. With a proportion of $5 \%$ of the phenotypic variance explained by the QTL, the detection power is equal to $74 \%$ and with a proportion of $2.5 \%$ of the phenotypic variance explained by the QTL, the detection power is equal to $28 \%$. The power calculations show a high probability of identifying SNP explaining at least $5 \%$ of the phenotypic variance in our study. Therefore, if a gene with a major effect on claw disorders would be segregating in the current population, it is likely that it would have been detected. The power was too low to detect genes with a moderate or small effect.

The GWAS signals detected in the current study are different from what has been reported in other GWAS. The first issue is that in several cases, only a single significant or suggestive SNP was detected in a region, whereas often several SNP in a region show a significant association. This could be due to QTL with a low MAF: 7 of the 10 significant SNP and 23 of the 45 suggestive SNP had one genotype with less than 50 cows and therefore have a low MAF $(<3 \%)$. The QTL with low MAF in general have a low detection power as they explain a small part of the variance (e.g., Pritchard, 2001; Cirulli and Goldstein, 2010). The QTL with low MAF might also be in low LD with SNP present on the SNP array due to ascertainment bias (Wray, 2005). Better coverage using SNP with low MAF might be needed to identify stronger associations (Lee et al., 2013). The second issue is that effects of SNP detected are large. Although studies have shown

Table 1. Single nucleotide polymorphisms significantly associated with sole ulcer [false discovery rate (FDR) $\leq 0.05$ ]

\begin{tabular}{|c|c|c|c|c|c|c|c|c|c|c|}
\hline BTA & $\begin{array}{l}\text { Position } \\
\text { (bp) }\end{array}$ & SNP name & $-\log _{10} P$ & FDR & \multicolumn{3}{|c|}{ No. of cows } & \multicolumn{3}{|c|}{ SNP effect } \\
\hline 8 & 5437200 & BTA-81490-no-rs & 5.20 & 0.02 & 101 & 677 & 992 & $0.07(0.03)$ & 0 & $-0.03(0.01)$ \\
\hline 8 & 74093999 & Hapmap43489-ВTA-121857 & 5.85 & 0.01 & 1,549 & 209 & 13 & $-0.01(0.02)$ & 0 & $0.28(0.06)$ \\
\hline 8 & 78533314 & ARS-BFGL-NGS-108587 & 5.44 & 0.02 & 6 & 142 & 1,623 & $0.38(0.06)$ & 0 & $0.001(0.02)$ \\
\hline 8 & 100873051 & ARS-BFGL-NGS-34028 & 6.26 & 0.01 & 51 & 518 & 1,202 & $0.15(0.03)$ & 0 & $-0.02(0.01)$ \\
\hline 22 & 14300175 & BTB-00834995 & 4.70 & 0.05 & 1,512 & 241 & 13 & $0.004(0.01)$ & 0 & $0.25(0.04)$ \\
\hline 22 & 15276355 & ARS-BFGL-NGS-3298 & 6.79 & 0.01 & 15 & 249 & 1,507 & $0.28(0.03)$ & 0 & $0.01(0.01)$ \\
\hline
\end{tabular}


that alleles with low frequencies can have large effects on complex traits (e.g., Mackay et al., 2012; Weber et al., 2012), the SNP detected in our cow data set are likely overestimated. The significant SNP associations in our study in general have a low MAF and explain a small part of the genetic variance. When the explained genetic variance is low, the detection power is low and effect sizes are likely overestimated (Lynch and Walsh, 1998). This relates to the effect known as the winner's curse (Ioannidis, 2008; Kraft, 2008). The effect sizes for the SNP that are validated based on the bull data are on average almost 4 times smaller as compared with the effect sizes in the cow data. Although SNP effects estimated based on the bull data are allele substitution effects and therefore not fully comparable, it illustrates that the effects reported in Table 1 are likely overestimates. The above-mentioned reasons for both issues might explain why only one significantly or suggestively associated SNP with large effect was detected in a region.

\section{Literature}

No other genome-wide association studies on claw disorders have been published. However, linkage studies (e.g., Ashwell et al., 2005; Buitenhuis et al., 2007) and a GWAS (Cole et al., 2011) have been published on traits which have been shown to be genetically correlated to claw disorders (van der Waaij et al., 2005; Laursen et al., 2009; van der Linde et al., 2010; Weber et al., 2013), for example, rear leg rear view, rear leg side view, foot angle, general feet and legs score, hock quality, and lameness. First we will discuss how the validated SNP in our study relate to findings in literature and subsequently other significant and suggestive results will be discussed.

The 3 validated SNP were located in chromosomal regions which have been associated with feet and leg conformation traits. The validated SNP ARS-BFGLNGS-113540 (31.3 Mbp) associated with SU in our study is located in the same region of BTA13 as marker UWCA25-BL42 (20-83 cM) associated with foot angle (Ashwell et al., 2005). Another marker detected by Ashwell et al. (2005) associated with foot angle, BMS1899BM4513 (0-76 cM), was located in the same region of BTA14 as validated SNP ARS-BFGL-NGS-4929 (64.0 Mbp) associated with $\mathrm{IH}$ in our study. The third validated SNP, BTB-00678060 (46.3 Mbp) associated with SU in our study, was located in the same region of BTA17 as marker CSSM9-OARFCB48 $(32.0 \mathrm{cM})$ associated with bone quality detected by Buitenhuis et al. (2007).

We searched for candidate genes by taking a 200,000bp window surrounding the 3 validated SNP. In the region of SNP ARS-BFGL-NGS-113540 on BTA13, the genes C1QL3 and PTER were located. In the region of SNP ARS-BFGL-NGS-4929 on BTA14, the genes AZIN1, TRNAE-UUC, KLF10, ODF1, and UBR5 were located, and in the region of SNP BTB-00678060 on BTA17, the genes SFSWAP, MMP17, ULK1, PUS1, EP400, LOC101906627, and LOC100138728 were located. However, none of the genes has an apparent function related to claw disorders. Eight suggestive and 3 significant SNP detected based on the cow data set were located close to associations with feet and leg conformation detected in previous research. The SNP ARS-BFGL-NGS-12807 on BTA5 at $71.8 \mathrm{Mbp}$ was suggestively associated with $\mathrm{SU}$ in our study. At almost the same location (71.7 Mbp), Cole et al. (2011) detected an association with general feet and leg score. Furthermore, in the same region (Lysmic-ETH10 at 72 cM) Hiendleder et al. (2003) detected a QTL associated with foot angle. Buitenhuis et al. (2007) detected a QTL on BTA8 (marker MCM64-CSSM047 at 92.0 cM) associated with foot angle and this appears to be in a region associated with SU in our study: 3 significant and 5 suggestive SNP in the region 67.8 to $106.6 \mathrm{Mbp}$. A linkage study by Hiendleder et al. (2003) showed an association of marker MILSTS077 on BTA13 (54 cM) with rear leg side view. This marker appears to be close to SNP ARS-BFGL-NGS-113236 (29.6 Mbp) associated with LAMIN in the current study. On BTA6, Hiendleder et al. (2003) detected marker FBN14 (88 $\mathrm{cM}$ ), which is associated with foot angle and appears to be close to SNP BTA-77057-no-rs (87.4 Mbp) associated with IH in the current study. Another linkage study detected marker BP7 on BTA6 $(85 \mathrm{cM})$, which is also located close to SNP BTA-77057-no-rs, and in their study it is associated with rear leg set (Schrooten et al., 2000).

The SNP on BTA18 position $58.7 \mathrm{Mbp}$ detected by Cole et al. (2011) and associated with rear leg side view was also detected in our study. In our study, this SNP was associated with $\mathrm{IH}$, but one genotype had only 3 observations. After removing this genotype, the SNP was no longer significant $(P>0.05)$. A recent study of Swalve et al. (2014) using a preselected set of 384 SNP detected a strong association on BTA21 with SH. The SNP detected by Swalve et al. (2014), SNP rs29017173, had a nominal $P$-value of 0.06 for SU in our study. The favorable SNP allele in our study is identical to Swalve et al. (2014). For other laminitis-related traits the nominal $P$-value of this SNP was higher than 0.20. Even though we did not find a significant $(\mathrm{FDR} \leq 0.05)$ or suggestive SNP (FDR $\leq 0.20)$ on BTA21 associated with $\mathrm{SH}$ or laminitis-related claw disorders, this result seem to confirm the SNP detected in the study of Swalve et al. (2014). 
Whether a cow was trimmed or not, the so-called trimming status of a cow reflects the need for trimming. One significant and one suggestive SNP association was detected, both located close to each other on BTA15. Ashwell et al. (2005) detected a QTL (BMS2684-HBB) located in the same region, associated with stature. The SNP ARS-BFGL-NGS-73559 on BTA26 position 44.7 Mbp, was associated with trimming status but had one genotype with only 2 observations, and when this genotype was removed the SNP was no longer significant $(P$ $>0.05)$. This SNP might still be interesting because it was situated within a region with 7 significant SNP detected by Cole et al. (2011), spanning from 39.3 to 49.2 Mbp.

One candidate gene (SORL1) for the trimming status trait was detected for both UA-IFASA-6898 and ARSBFGL-NGS-57210 within a 200,000-bp window, but does not have an apparent function related to the trait.

Even though we indicated that many significant and suggestive SNP were located in close proximity to SNP identified in previous studies on claw and leg conformation traits, the overlap is not very high. This is most likely due to the rather low to moderate genetic correlations between claw and leg conformation traits and claw disorders, ranging from -0.07 to 0.69 (van der Waaij et al., 2005; Laursen et al., 2009).

\section{Future Implications}

More research with a larger number of animals is needed to obtain a higher power and find more or stronger associations. Claw problems are likely affected by many genes, each explaining a small part of the variation. This complicates identifying causal variants. Further, our results suggest that claw disorders are affected by rare variants with large effects. Identifying causal variants with low MAF might require a SNP array with higher density (Manolio et al., 2009; Lee et al., 2013). Genomic selection can be used to reduce the incidence of claw disorders, requiring large reference populations.

\section{CONCLUSIONS}

The current study is to our knowledge the first GWAS, which revealed significant and suggestive SNP associated with different claw disorders and the need for trimming. In total, 11 significant and 46 suggestive SNP associations were detected for claw disorders and trimming status on 20 chromosomes. Some suggestive SNP were closely located to SNP detected in previous research on feet and leg conformation traits. Another interesting finding was that 3 of the suggestive SNP could be validated in an independent data set of bulls.
Also, these $3 \mathrm{SNP}$ were located in the same region on the genome as QTL detected in previous research associated with feet and leg conformation traits. Genes with a major effect were not detected. Likely, many genes each explaining a small proportion of the genetic variance influence the development of claw disorders but the power of the current study was too low to verify this.

\section{ACKNOWLEDGMENTS}

This study was financially supported by Genes Diffusion, Douai, France. The authors thank the claw trimmers, technicians, farmers, and all the people involved for their major effort in collecting data and making it available for us. Amélie Vallée (Genes Diffusion, Douai, France) is acknowledged for her contribution in obtaining the genotypes.

\section{REFERENCES}

Ashwell, M. S., Y. Da, C. P. Van Tassell, P. M. Vanraden, R. H. Miller, and C. E. Rexroad Jr.. 1998a. Detection of putative loci affecting milk production and composition, health, and type traits in a United States Holstein population. J. Dairy Sci. 81:3309-3314.

Ashwell, M. S., Y. Da, P. M. Vanraden, C. E. Rexroad Jr., and R. H. Miller. 1998b. Detection of putative loci affecting conformational type traits in an elite population of United States Holsteins using microsatellite markers. J. Dairy Sci. 81:1120-1125.

Ashwell, M. S., D. W. Heyen, J. I. Weller, M. Ron, T. S. Sonstegard, C. P. Van Tassell, and H. A. Lewin. 2005. Detection of quantitative trait loci influencing conformation traits and calving ease in Holstein-Friesian cattle. J. Dairy Sci. 88:4111-4119.

Ball, R. 2010. ldDesign: Design of experiments for detection of linkage disequilibrium. R package version 1.2-0. http://CRAN.R-project. org $/$ package $=$ ldDesign.

Boichard, D., C. Grohs, F. Bourgeois, F. Cerqueira, R. Faugeras, A. Neau, R. Rupp, Y. Amigues, M. Y. Boscher, and H. Levéziel. 2003. Detection of genes influencing economic traits in three French dairy cattle breeds. Genet. Sel. Evol. 35:77-101.

Bruijnis, M. R. N., B. Beerda, H. Hogeveen, and E. N. Stassen. 2012a. Foot disorders in dairy cattle: Impact on cow and dairy farmer. Anim. Welf. 21(Suppl. 1):33-40.

Bruijnis, M. R. N., B. Beerda, H. Hogeveen, and E. N. Stassen. 2012b. Assessing the welfare impact of foot disorders in dairy cattle by a modeling approach. Animal 6:962-970.

Buitenhuis, A. J., M. S. Lund, J. R. Thomasen, B. Thomsen, V. H. Nielsen, C. Bendixen, and B. Guldbrandtsen. 2007. Detection of quantitative trait loci affecting lameness and leg conformation traits in Danish Holstein cattle. J. Dairy Sci. 90:472-481.

Chanock, S. J., T. Manolio, M. Boehnke, E. Boerwinkle, D. J. Hunter, G. Thomas, J. N. Hirschhorn, G. Abecasis, D. Altshuler, J. E. Bailey-Wilson, L. D. Brooks, L. R. Cardon, M. Daly, P. Donnelly, J. F. Fraumeni Jr., N. B. Freimer, D. S. Gerhard, C. Gunter, A. E. Guttmacher, M. S. Guyer, E. L. Harris, J. Hoh, R. Hoover, C. A. Kong, K. R. Merikangas, C. C. Morton, L. J. Palmer, E. G. Phimister, J. P. Rice, J. Roberts, C. Rotimi, M. A. Tucker, K. J. Vogan, S. Wacholder, E. M. Wijsman, D. M. Winn, and F. S. Collins. 2007. Replicating genotype-phenotype associations. Nature 447:655-660.

Cirulli, E. T., and D. B. Goldstein. 2010. Uncovering the roles of rare variants in common disease through whole-genome sequencing. Nat. Rev. Genet. 11:415-425.

Cole, J. B., G. R. Wiggans, L. Ma, T. S. Sonstegard, T. J. Lawlor Jr., B. A. Crooker, C. P. Van Tassell, J. Yang, S. Wang, L. K. 
Matukumalli, and Y. Da. 2011. Genome-wide association analysis of thirty one production, health, reproduction and body conformation traits in contemporary U.S. Holstein cows. BMC Genomics 12:408.

Enting, H., D. Kooij, A. A. Dijkhuizen, R. B. M. Huirne, and E. N. Noordhuizen-Stassen. 1997. Economic losses due to clinical lameness in dairy cattle. Livest. Prod. Sci. 49:259-267.

Gilmour, A. R., B. J. Gogel, B. R. Cullis, and R. Thompson. 2009. ASReml User Guide Release 3.0. VSN International Ltd., Hemel Hempstead, UK.

Goddard, M. E., and B. J. Hayes. 2009. Mapping genes for complex traits in domestic animals and their use in breeding programmes. Nat. Rev. Genet. 10:381-391.

Hayes, B. 2013. Overview of Statistical Methods for Genome-Wide Association Studies (GWAS). Pages 149-169 in Genome-Wide Association Studies and Genomic Prediction. Methods in Molecular Biology. Vol. 1019. G. Cedric, J. van der Werf, and B. Hayes, ed. Humana Press, New York, NY.

Hiendleder, S., H. Thomsen, N. Reinsch, J. Bennewitz, B. Leyhe-Horn, C. Looft, N. Xu, I. Medjugorac, I. Russ, C. Kühn, G. A. Brockmann, J. Blümel, B. Brenig, F. Reinhardt, R. Reents, G. Averdunk, M. Schwerin, M. Förster, M. E. Kalm, and G. Erhardt. 2003. Mapping of QTL for body conformation and behavior in cattle. J. Hered. 94:496-506.

Hirschhorn, J. N., and M. J. Daly. 2005. Genome-wide association studies for common diseases and complex traits. Nat. Rev. Genet. 6:95-108.

Ioannidis, J. P. A. 2008. Why most discovered true associations are inflated. Epidemiology 19:640-648.

Kraft, P. 2008. Curses - winner's and otherwise - in genetic epidemiology. Epidemiology 19:649-651.

Laursen, M. V., D. Boelling, and T. Mark. 2009. Genetic parameters for claw and leg health, foot and leg conformation, and locomotion in Danish Holstein. J. Dairy Sci. 92:1770-1777.

Lee, S. H., D. Harold, D. R. Nyholt, M. E. Goddard, K. T. Zondervan, J. Williams, G. W. Montgomery, N. R. Wray, P. M. Visscher, ANZGene Consortium, International Endogene Consortium, and Genetic and Environmental Risk for Alzheimer's Disease Consortium. 2013. Estimation and partitioning of polygenic variation captured by common SNPs for Alzheimer's disease, multiple sclerosis and endometriosis. Hum. Mol. Genet. 22:832-841.

Luo, Z. W. 1998. Detecting linkage disequilibrium between a polymorphic marker locus and a trait locus in natural populations. Heredity 80:198-208.

Lynch, M., and J. B. Walsh. 1998. Genetics and Analysis of Quantitative Traits. Sinauer Associates, Sunderland, MA.

Mackay, T. F. C., S. Richards, E. A. Stone, A. Barbadilla, J. F. Ayroles, D. Zhu, S. Casillas, Y. Han, M. M. Magwire, J. M. Cridland, M. F. Richardson, R. R. H. Anholt, M. Barrón, C. Bess, K. P. Blankenburg, M. A. Carbone, D. Castellano, L. Chaboub, L. Duncan, Z. Harris, M. Javaid, J. C. Jayaseelan, S. N. Jhangiani, K. W. Jordan, F. Lara, F. Lawrence, S. L. Lee, P. Librado, R. S. Linheiro, R. F. Lyman, A. J. Mackey, M. Munidasa, D. M. Muzny, L. Nazareth, I. Newsham, L. Perales, L.-L. Pu, C. Qu, M. Ràmia, J. G. Reid, S. M. Rollmann, J. Rozas, N. Saada, L. Turlapati, K. C. Worley, Y.-Q. Wu, A. Yamamoto, Y. Zhu, C. M. Bergman, K. R. Thornton, D. Mittelman, and R. A. Gibbs. 2012. The Drosophila melanogaster Genetic Reference Panel. Nature 482:173-178.

Manolio, T. A., F. S. Collins, N. J. Cox, D. B. Goldstein, L. A. Hindorff, D. J. Hunter, M. I. McCarthy, E. M. Ramos, L. R. Cardon,
A. Chakravarti, J. H. Cho, A. P. Feinberg, A. E. Guttmacher A. Kong, L. Kruglyak, E. Mardis, C. N. Rotimi, M. Slatkin, D. Valle, A. S. Whittemore, M. Boehnke, A. Clark, E. E. Eichler, G. Gibson, J. L. Haines, T. F. C. Mackay, S. A. McCarroll, and P. M. Visscher. 2009. Finding the missing heritability of complex diseases. Nature 461:747-753.

Manske, T., J. Hultgren, and C. Bergsten. 2002. Prevalence and interrelationships of hoof lesions and lameness in Swedish dairy cows. Prev. Vet. Med. 54:247-263.

Matukumalli, L. K., C. T. Lawley, R. D. Schnabel, J. F. Taylor, M. F. Allan, M. P. Heaton, J. O'Connell, S. S. Moore, T. P. L. Smith T. S. Sonstegard, and C. P. Van Tassell. 2009. Development and characterization of a high density SNP genotyping assay for cattle. PLoS ONE 4:e5350.

Miglior, F., B. L. Muir, and B. J. Van Doormaal. 2005. Selection Indices in Holstein cattle of various countries. J. Dairy Sci. 88:12551263

Pirinen, M., P. Donnelly, and C. A. Spencer. 2013. Efficient computation with a linear mixed model on large-scale data sets with applications to genetic studies. Ann. Appl. Stat. 7:369-390.

Pritchard, J. K. 2001. Are rare variants responsible for susceptibility to complex diseases? Am. J. Hum. Genet. 69:124-137.

Schrooten, C., H. Bovenhuis, W. Coppieters, and J. A. M. Van Arendonk. 2000. Whole genome scan to detect quantitative trait loci for conformation and functional traits in dairy cattle. J. Dairy Sci. 83:795-806.

Storey, J. D., and R. Tibshirani. 2003. Statistical significance for genome-wide studies. Proc. Natl. Acad. Sci. USA 100:9440-9445.

Swalve, H. H., C. Floren, M. Wensch-Dorendorf, K. Schöpke, R. Pijl, K. Wimmers, and B. Brenig. 2014. A study based on records taken at time of hoof trimming reveals a strong association between the IQ motif-containing GTPase-activating protein 1 (IQGAP1) gene and sole hemorrhage in Holstein cattle. J. Dairy Sci. 97:507-519.

Tellam, R. L., D. G. Lemay, C. P. Van Tassell, H. A. Lewin, K. C. Worley, and C. G. Elsik. 2009. Unlocking the bovine genome. BMC Genomics 10:193.

van der Linde, C., G. de Jong, E. P. C. Koenen, and H. Eding. 2010. Claw health index for Dutch dairy cattle based on claw trimming and conformation data. J. Dairy Sci. 93:4883-4891.

van der Spek, D., J. A. M. Van Arendonk, A. A. A. Vallée, and H. Bovenhuis. 2013. Genetic parameters for claw disorders and the effect of preselecting cows for trimming. J. Dairy Sci. 96:6070-6078.

van der Waaij, E. H., M. Holzhauer, E. Ellen, C. Kamphuis, and G. de Jong. 2005. Genetic parameters for claw disorders in Dutch dairy cattle and correlations with conformation traits. J. Dairy Sci. 88:3672-3678

Visscher, P. M. 2008. Sizing up human height variation. Nat. Genet. 40:489-490.

Weber, A., E. Stamer, W. Junge, and G. Thaller. 2013. Genetic parameters for lameness and claw and leg diseases in dairy cows. J. Dairy Sci. 96:3310-3318.

Weber, A. L., G. F. Khan, M. M. Magwire, C. L. Tabor, T. F. C. Mackay, and R. R. H. Anholt. 2012. Genome-wide association analysis of oxidative stress resistance in Drosophila melanogaster. PLoS ONE 7:e34745.

Wray, N. R. 2005. Allele frequencies and the r2 measure of linkage disequilibrium: Impact on design and interpretation of association studies. Twin Res. Hum. Genet. 8:87-94. 


\section{APPENDIX}

Table A1. Single nucleotide polymorphism associations for claw disorders and the combination of laminitis-related claw disorders (double sole, sole hemorrhage, sole ulcer, and white line separation), that were suggestively [false discovery rate (FDR) $\leq 0.20$ ] associated

\begin{tabular}{|c|c|c|c|c|c|c|c|c|c|c|c|}
\hline \multirow[b]{2}{*}{ BTA } & \multirow{2}{*}{$\begin{array}{l}\text { Position } \\
\text { (bp) }\end{array}$} & \multirow[b]{2}{*}{ SNP name } & \multirow[b]{2}{*}{ Claw disorder } & \multirow[b]{2}{*}{$-\log _{10} P$} & \multirow[b]{2}{*}{ FDR } & \multicolumn{3}{|c|}{ No. of cows } & \multicolumn{3}{|c|}{ SNP effect } \\
\hline & & & & & & $\mathrm{AA}$ & $\mathrm{AB}$ & $\mathrm{BB}$ & $\mathrm{AA}(\mathrm{SE})$ & $\mathrm{AB}(\mathrm{SE})$ & $\mathrm{BB}(\mathrm{SE})$ \\
\hline 1 & 18285474 & Hapmap33466-BTA-107178 & Sole ulcer & 3.87 & 0.15 & 1,335 & 405 & 28 & $-0.02(0.01)$ & 0 & $0.15(0.03)$ \\
\hline 1 & 93639215 & BTA-48243-no-rs & Laminitis related & 4.41 & 0.17 & 497 & 898 & 379 & $-0.15(0.03)$ & 0 & $-0.02(0.07)$ \\
\hline 5 & 71778071 & ARS-BFGL-NGS-12807 & Sole ulcer & 3.81 & 0.16 & 68 & 520 & 1,183 & $0.11(0.03)$ & 0 & $0.02(0.01)$ \\
\hline 6 & 87365840 & BTA-77057-no-rs & Interdigital hyperplasia & 5.17 & 0.06 & 1,204 & 506 & 57 & $-0.01(0.01)$ & 0 & $0.16(0.04)$ \\
\hline 7 & 61196630 & ARS-BFGL-NGS-5134 & Interdigital hyperplasia & 4.13 & 0.12 & 726 & 823 & 222 & $0.02(0.01)$ & 0 & $0.08(0.02)$ \\
\hline 7 & 68156093 & Hapmap54765-rs29012520 & Interdigital hyperplasia & 3.87 & 0.19 & 1,362 & 389 & 20 & $-0.01(0.01)$ & 0 & $0.22(0.05)$ \\
\hline 7 & 68281468 & ARS-BFGL-NGS-65419 & Sole ulcer & 3.94 & 0.13 & 172 & 822 & 777 & $0.08(0.03)$ & 0 & $0.03(0.01)$ \\
\hline 8 & 8953354 & ARS-BFGL-NGS-69316 & Interdigital hyperplasia & 3.81 & 0.20 & 22 & 404 & 1,345 & $0.18(0.04)$ & 0 & $0.04(0.01)$ \\
\hline 8 & 24869885 & BTB-01052583 & Interdigital hyperplasia & 4.17 & 0.12 & 1,500 & 261 & 10 & $0.29(0.06)$ & 0 & $-0.03(0.02)$ \\
\hline 8 & 25012621 & BTB-01052539 & Interdigital hyperplasia & 4.17 & 0.12 & 10 & 261 & 1,500 & $-0.03(0.02)$ & 0 & $0.29(0.06)$ \\
\hline 8 & 25035564 & ARS-BFGL-NGS-5492 & Interdigital hyperplasia & 4.17 & 0.12 & 10 & 261 & 1,500 & $0.29(0.06)$ & 0 & $-0.03(0.02)$ \\
\hline 8 & 43241581 & ARS-BFGL-NGS-4797 & Interdigital hyperplasia & 4.37 & 0.12 & 564 & 888 & 319 & $0.06(0.01)$ & 0 & $0.02(0.02)$ \\
\hline 8 & 67822026 & ARS-BFGL-NGS-115977 & Sole ulcer & 4.40 & 0.08 & 9 & 204 & 1,558 & $0.26(0.05)$ & 0 & $0.02(0.02)$ \\
\hline 8 & 67846594 & ARS-BFGL-NGS-40613 & Sole ulcer & 4.34 & 0.09 & 9 & 203 & 1,558 & $0.26(0.05)$ & 0 & $0.02(0.02)$ \\
\hline 8 & 100537840 & ARS-BFGL-NGS-79358 & Sole ulcer & 4.25 & 0.10 & 46 & 510 & 1,215 & $0.13(0.02)$ & 0 & $-0.01(0.01)$ \\
\hline 8 & 101044054 & ARS-BFGL-NGS-112179 & Sole ulcer & 4.22 & 0.10 & 1,013 & 657 & 101 & $-0.02(0.01)$ & 0 & $0.07(0.02)$ \\
\hline 8 & 106648392 & Hapmap27876-BTA-147931 & Sole ulcer & 3.67 & 0.20 & 9 & 217 & 1545 & $0.32(0.06)$ & 0 & $-0.01(0.02)$ \\
\hline 9 & 1333028 & Нарmap41734-ВTA-103209 & Sole ulcer & 3.94 & 0.13 & 1,125 & 578 & 68 & $-0.03(0.01)$ & 0 & $0.07(0.04)$ \\
\hline 9 & 79256833 & Hapmap26214-BTA-163696 & Sole ulcer & 3.94 & 0.13 & 15 & 255 & 1,501 & $0.23(0.04)$ & 0 & $0.004(0.01)$ \\
\hline 9 & 83904725 & ARS-BFGL-NGS-35130 & Interdigital hyperplasia & 4.97 & 0.06 & 52 & 494 & 1,225 & $0.15(0.05)$ & 0 & $-0.02(0.01)$ \\
\hline 9 & 85494205 & Hapmap59396-rs29023560 & Interdigital hyperplasia & 4.07 & 0.13 & 1,244 & 459 & 47 & $-0.02(0.01)$ & 0 & $0.15(0.02)$ \\
\hline 9 & 90283190 & BTB-00404361 & Interdigital hyperplasia & 4.18 & 0.12 & 1494 & 270 & 6 & $-0.06(0.02)$ & 0 & $0.21(0.12)$ \\
\hline 10 & 31162777 & BTB-00416921 & Sole ulcer & 4.18 & 0.11 & 25 & 399 & 1347 & $0.16(0.03)$ & 0 & $-0.02(0.01)$ \\
\hline 10 & 44082049 & BTB-01413108 & Sole ulcer & 4.07 & 0.11 & 1,662 & 109 & 0 & $-0.09(0.02)$ & 0 & - \\
\hline 11 & 14134626 & Hapmap31534-BTA-26223 & Interdigital hyperplasia & 3.84 & 0.19 & 1,027 & 655 & 89 & $0.05(0.01)$ & 0 & $0.07(0.03)$ \\
\hline 12 & 62307557 & BTA-85739-no-rs & Laminitis related & 4.34 & 0.17 & 124 & 721 & 926 & $0.10(0.09)$ & 0 & $0.14(0.03)$ \\
\hline 12 & 62615139 & Нарmap27169-ВTA-141662 & Laminitis related & 4.27 & 0.17 & 110 & 685 & 976 & $0.12(0.09)$ & 0 & $0.13(0.03)$ \\
\hline 13 & 29647662 & ARS-BFGL-NGS-113236 & Laminitis related & 4.30 & 0.17 & 424 & 908 & 439 & $-0.16(0.08)$ & 0 & $-0.02(0.04)$ \\
\hline 13 & 31304022 & ARS-BFGL-NGS-113540 & Sole ulcer & 4.61 & 0.06 & 1,447 & 311 & 13 & $0.02(0.01)$ & 0 & $0.28(0.05)$ \\
\hline 14 & 6203679 & Hapmap32486-BTC-056478 & Sole ulcer & 4.37 & 0.08 & 1,136 & 576 & 59 & $0.03(0.01)$ & 0 & $0.10(0.03)$ \\
\hline 14 & 63972246 & ARS-BFGL-NGS-4929 & Interdigital hyperplasia & 4.69 & 0.07 & 53 & 497 & 1,221 & $0.17(0.05)$ & 0 & $-0.00(0.01)$ \\
\hline 15 & 52875986 & BTB-00600391 & Double sole & 5.08 & 0.07 & 6 & 239 & 1,521 & $0.51(0.09)$ & 0 & $0.03(0.02)$ \\
\hline 15 & 67131730 & BTB-01649233 & Sole ulcer & 4.31 & 0.09 & 8 & 196 & 1,567 & $0.27(0.05)$ & 0 & $-0.02(0.02)$ \\
\hline 17 & 46296022 & BTB-00678060 & Sole ulcer & 4.09 & 0.11 & 6 & 290 & 1,475 & $0.44(0.09)$ & 0 & $0.01(0.01)$ \\
\hline 18 & 25022927 & ARS-BFGL-NGS-24004 & Sole ulcer & 4.08 & 0.11 & 316 & 857 & 598 & $0.04(0.02)$ & 0 & $-0.02(0.01)$ \\
\hline 18 & 25046677 & ARS-BFGL-NGS-107737 & Sole ulcer & 4.08 & 0.11 & 598 & 856 & 316 & $-0.02(0.01)$ & 0 & $0.04(0.02)$ \\
\hline 20 & 37721846 & BTA-50515-no-rs & Laminitis related & 5.25 & 0.07 & 970 & 678 & 123 & $-0.01(0.03)$ & 0 & $0.27(0.06)$ \\
\hline 20 & 48937082 & ARS-BFGL-NGS-59274 & Laminitis related & 4.27 & 0.17 & 878 & 748 & 144 & $-0.02(0.03)$ & 0 & $0.22(0.05)$ \\
\hline 20 & 64084187 & BTB-00795527 & Interdigital hyperplasia & 4.38 & 0.12 & 1,440 & 312 & 19 & $0.03(0.02)$ & 0 & $0.23(0.04)$ \\
\hline 20 & 67899804 & ARS-BFGL-NGS-6648 & Interdigital hyperplasia & 4.32 & 0.12 & 15 & 359 & 1,398 & $0.29(0.05)$ & 0 & $0.02(0.02)$ \\
\hline 20 & 71498820 & ARS-BFGL-NGS-13702 & Laminitis related & 4.58 & 0.16 & 70 & 619 & 1,082 & $-0.05(0.11)$ & 0 & $0.14(0.03)$ \\
\hline 21 & 7526820 & Hapmap44255-BTA-52888 & Sole ulcer & 3.94 & 0.13 & 655 & 889 & 227 & $-0.01(0.01)$ & 0 & $0.06(0.02)$ \\
\hline 23 & 15725194 & ARS-BFGL-NGS-23572 & Sole ulcer & 3.94 & 0.13 & 6 & 88 & 1,677 & $0.36(0.06)$ & 0 & $0.03(0.02)$ \\
\hline 24 & 8435459 & ARS-BFGL-NGS-107083 & Interdigital hyperplasia & 4.15 & 0.12 & 1,513 & 242 & 8 & $0.02(0.02)$ & 0 & $0.35(0.07)$ \\
\hline 26 & 9195089 & BTA-111275-no-rs & Interdigital hyperplasia & 4.91 & 0.06 & 780 & 805 & 186 & $-0.01(0.01)$ & 0 & $0.09(0.03)$ \\
\hline
\end{tabular}

